\title{
Significance of GSTP1 for predicting the prognosis and chemotherapeutic efficacy in esophageal squamous cell carcinoma
}

\author{
YUSUKE YAMAMOTO $^{1}$, HIROTAKA KONISHI ${ }^{1}$, DAISUKE ICHIKAWA ${ }^{1}$, TOMOHIRO ARITA ${ }^{1}$, \\ KATSUTOSHI SHODA $^{1}$, SHUHEI KOMATSU ${ }^{1}$, ATSUSHI SHIOZAKI ${ }^{1}$, HISASHI IKOMA ${ }^{1}$, \\ HITOSHI FUJIWARA ${ }^{1}$, KAZUMA OKAMOTO ${ }^{1}$, TOSHIYA OCHIAI ${ }^{1}$, JUN INOUE ${ }^{2}$, \\ JOHJI INAZAWA ${ }^{2}$ and EIGO OTSUJI ${ }^{1}$ \\ ${ }^{1}$ Division of Digestive Surgery, Department of Surgery, Kyoto Prefectural University of Medicine, Kyoto; \\ ${ }^{2}$ Department of Molecular Cytogenetics, Medical Research Institute, \\ Tokyo Medical and Dental University, Tokyo, Japan
}

Received April 9, 2013; Accepted June 12, 2013

DOI: $10.3892 / o r .2013 .2606$

\begin{abstract}
Glutathione S-transferases (GSTs) have been reported to be activated in several types of cancers, including esophageal squamous cell carcinoma (ESCC). The aim of the present study was to investigate whether GSTP1 protein expression is a useful predictor of the clinical outcome or drug resistance in ESCC. Immunohistochemistry was conducted with 75 ESCC resected specimens using a monoclonal antibody against GSTP1. The patients were divided into two groups according to the degree of GSTP1 staining, and the relationship between the GSTP1 level and the clinicopathological features was examined. Seventy-five patients were divided into low (grade 1, $n=36$ ) and high (grade 2, n=39) GSTP1 expression groups. The overall survival was significantly worse in the grade 2 patients than in the grade 1 patients (5-year survival rate, 78.5 vs. $51.2 \%$; $\mathrm{p}=0.027$ ). Cox proportional hazard analysis revealed that macroscopic type 3 or 4 disease $(\mathrm{p}=0.001)$, lymph node metastasis $(\mathrm{p}=0.010)$, and high GSTP1 expression $(\mathrm{p}=0.029)$ were independent predictors of a poor prognosis. With regard to the subgroup analysis among the 31 patients undergoing adjuvant chemotherapy, the grade 2 patients had a worse prognosis than did the grade 1 patients (5-year survival rate, 45.0 vs. $81.8 \%$; $\mathrm{p}=0.081$ ). This tendency was not observed in the subgroup without adjuvant chemotherapy (5-year survival rate, 51.7 vs. 59.9\%; p=0.979). In conclusion, the GSTP1 expression is a good predictor of prognosis, and it may be closely related to the chemotherapeutic efficacy of 5-FU plus cisplatin in ESCC patients.
\end{abstract}

Correspondence to: Dr Hirotaka Konishi, Division of Digestive Surgery, Department of Surgery, Kyoto Prefectural University of Medicine, 465 Kajii-cho, Kamigyo-ku, Kyoto 6028566, Japan

E-mail: h-koni7@koto.kpu-m.ac.jp

Key words: glutathione S-transferase P1, esophageal squamous cell carcinoma, chemotherapeutic efficacy

\section{Introduction}

Esophageal carcinoma is the sixth most common cause of cancer-related death among adult malignant tumors, and it is considered to possess a relatively high malignant potential (1-5). Squamous cell carcinoma is the predominant cellular type of esophageal cancer worldwide, although the incidence of esophageal adenocarcinoma has been increasing in Western countries (6). More recent advances in surgical techniques, chemotherapy and radiotherapy have resulted in an improvement in the prognosis of esophageal squamous cell carcinoma (ESCC) (7); however, the long-term outcomes remain unacceptable. It is important to detect more useful predictors of the prognosis and efficacy of chemotherapy for the further improvement of the prognosis of ESCC patients.

Many genetic and epigenetic alterations have been reported in ESCC. In the present study, we focused on the expression of glutathione S-transferase (GST) P1 protein, which is the main GST expressed in the human esophagus. The GST family consists of a group of important phase II drug-metabolizing enzymes that is instrumental in providing cell protection or detoxification of toxic substances and anticancer drugs through conjugation with glutathione (GSH) (8). GSTP1 is widely expressed in normal tissues, while the enzyme activity has been shown to be highly overexpressed in several types of cancers, for example, blood, head and neck, lung, colorectal, esophagus and breast cancers (9-13). The high expression level of GSTP1 has been reported to be regulated by inflammation, various chemical carcinogens, the expression of $\mathrm{Nrf} 2$ and other factors. Thus, overexpression of GSTP1 may influence the clinical outcome or the resistance to anticancer drugs. However, the available information on the association between the degree of GSTP1 expression and the prognosis of ESCC is conflicting (14).

In the present study, we simply evaluated the immunohistochemical expression of GSTP1 in resected ESCC specimens and investigated whether GSTP1 expression is associated with the clinical outcome and the response to adjuvant chemotherapy. 


\section{Patients and methods}

Study population. We selected 75 patients who underwent macroscopically curative right-transthoracic esophagectomy with extensive lymph node dissection for ESCC between January 2000 and December 2009 at the Division of Digestive Surgery, Department of Surgery, Kyoto Prefectural University of Medicine, Kyoto, Japan. Of the 75 patients, 14 (19\%) patients underwent three-field lymph node dissection (cervical, mediastinal and abdominal nodes), while 61 (81\%) patients underwent two-field lymph node dissection (mediastinal and abdominal nodes) under pre- or intra-operative diagnosis (15). Thirty-one of the 75 patients $(41 \%)$ received post-operative adjuvant therapy, high-dose FP or low-dose FP plus oral fluoropyrimidine [5-FU (150-200 mg/body/day) or UFT (300-400 mg/body/day)] (16) and 4 patients were treated with pre-operative chemotherapy, high-dose FP [5-FU $\left(800 \mathrm{mg} / \mathrm{m}^{2} /\right.$ day, days $\left.1-5\right)$ plus cisplatin $\left(80 \mathrm{mg} / \mathrm{m}^{2} /\right.$ day, day 1$\left.)\right]$, followed by planned esophagectomy. We excluded the patients who underwent neoadjuvant chemo-radiation therapy. Staging was based principally on the International Union Against Cancer (UICC)/ TNM Classification of Malignant Tumors, 7th edition (17). The macroscopic type was classified as follows: type 0 , macroscopic early cancer; type 1 , polypoid tumors; type 2 , ulcerated carcinomas with sharply demarcated and raised margins; type 3 , ulcerated carcinomas without definite limits, infiltration into the surrounding wall; type 4 , diffusely infiltrating carcinomas in which ulceration is usually not a marked feature.

Postsurgical management. Following discharge from the hospital, the patients were regularly monitored in the outpatient clinic at intervals of 3 months for the first 2 years and at intervals of 6 months thereafter. Multi-slice computed tomography of the neck, chest and upper abdomen was performed every 6 months. Since 2007, positron emission tomography with computed tomography has been used in screening for recurrence $(18,19)$.

All recurrent tumors were evaluated using imaging studies. Of the 32 patients with recurrent tumors, 18 received intensive treatment: 10 received chemoradiotherapy, 1 received lymphadenectomy, 8 received chemotherapy; and 14 received the best supportive care.

Cell lines and western blotting. Each cell line was purchased from the Cell Resource Center of Tohoku University, Riken Bio Resource Center, or the American Type Culture Collection. Whole-cell lysates were prepared in SDS sample buffer, resolved by SDS-PAGE and transferred to PVDF membranes. After blocking with TBS containing 0.05\% Tween-20 and 5\% non-fat dry milk for $1 \mathrm{~h}$, each membrane was incubated with an antibody overnight. The primary antibodies and dilutions were anti-GSTP1 (1/500, HPA019779; Sigma-Aldrich) and anti-GAPDH (1/4,000, sc-25778; Santa Cruz Biotechnology, Inc.) antibodies. The membrane was washed and exposed to horseradish peroxidase-conjugated secondary antibody (at 1/5,000, \#7074S; Cell Signaling Technology). The bound antibodies were visualized with an HRP staining solution or with an ECL Western Detection kit on an Image Quant LAS 500 (GE Healthcare) according to the manufacturer's instructions (Cell Signaling Technology).
Immunohistochemistry. Tumor samples were fixed with $10 \%$ formaldehyde in PBS, embedded in paraffin, and sectioned into $5-\mu \mathrm{m}$ slices. After deparaffinization by xylene and rehydration with ethanol, antigen retrieval was performed by boiling in Dako REAL Red Target Retrieval Solution (pH 6.0) at $95^{\circ} \mathrm{C}$ for $30 \mathrm{~min}$ and the sections were treated with $0.3 \%$ hydrogen peroxide in methanol at room temperature for $20 \mathrm{~min}$ to inactivate the endogenous peroxidase. After treatment with Block Ace (Vectastain Elite ABC universal kit; Vector Laboratories, Inc., Burlingame, CA, USA) for $30 \mathrm{~min}$ at room temperature, the sections were incubated at $4^{\circ} \mathrm{C}$ overnight with a primary antibody against GSTP1 (1:500 dilution). The avidin-biotinperoxidase complex system (Vectastain Elite ABC universal kit) was used for secondary antibody detection and color development with diaminobenzidine tetrahydrochloride at room temperature for $30 \mathrm{~min}$. The slides were lightly counterstained with hematoxylin.

The patients were divided into two groups, grade 1 and 2, according to the degree of GSTP1 expression. Tissues of grade 2 were defined as those with even staining of at least $90 \%$ of the cancer area (Fig. 1B-a and -b) and tissues of grade 1 were defined as areas with spotty staining corresponding to $<90 \%$ of the cancer area (Fig. 1B-c and -d).

Inter-observer reproducibility for identifying the immunohistological characteristics. The reproducibility of the grading classification was tested by asking another independent observer (K.H.) to blindly review all of the examples. This observer was not provided with any clinical information regarding the outcomes of the patients. The reproducibility was tested by obtaining the $\kappa$-scores according to the widely used statistical chart that grades the strength of agreement to six categories [poor ( $\kappa$-score, $<0.00)$, slight $(0.00-0.20)$, fair (0.21-0.40), moderate (0.41-0.60), substantial (0.61-0.80) and almost perfect (0.81-1.00)] (20).

Statistical analysis. We performed univariate analyses of the 15 clinical and pathologic factors that were potentially associated with overall survival. Survival was calculated using the Kaplan Meier method and compared between groups using the log-rank test. A multivariate analysis using the Cox hazards model was performed to identify independent predictors of survival.

The relationship of GSTP1 expression and 10 pathological factors was compared using the Chi-squared test with Yates correction. All significant factors determined by the univariate analysis were entered into a multivariate regression analysis to identify independent factors. These tests were one-tailed and a $\mathrm{p}<0.05$ was considered to be statistically significant. All statistical analyses were performed using the SPSS for Windows 11.5 software program (SPSS, Chicago, IL, USA).

\section{Results}

GSTP1 protein expression in the ESCC cell lines. We performed a western blot analysis with an antibody against GSTP1 in 6 ESCC cell lines (TE2, TE5, TE9, TE13, KYSE70 and KYSE170) and a normal fibroblast cell line, WI-38. The GSTP1 protein expression level was upregulated in all of the ESCC cell lines compared with the level in the WI-38 cells (Fig. 1A). 

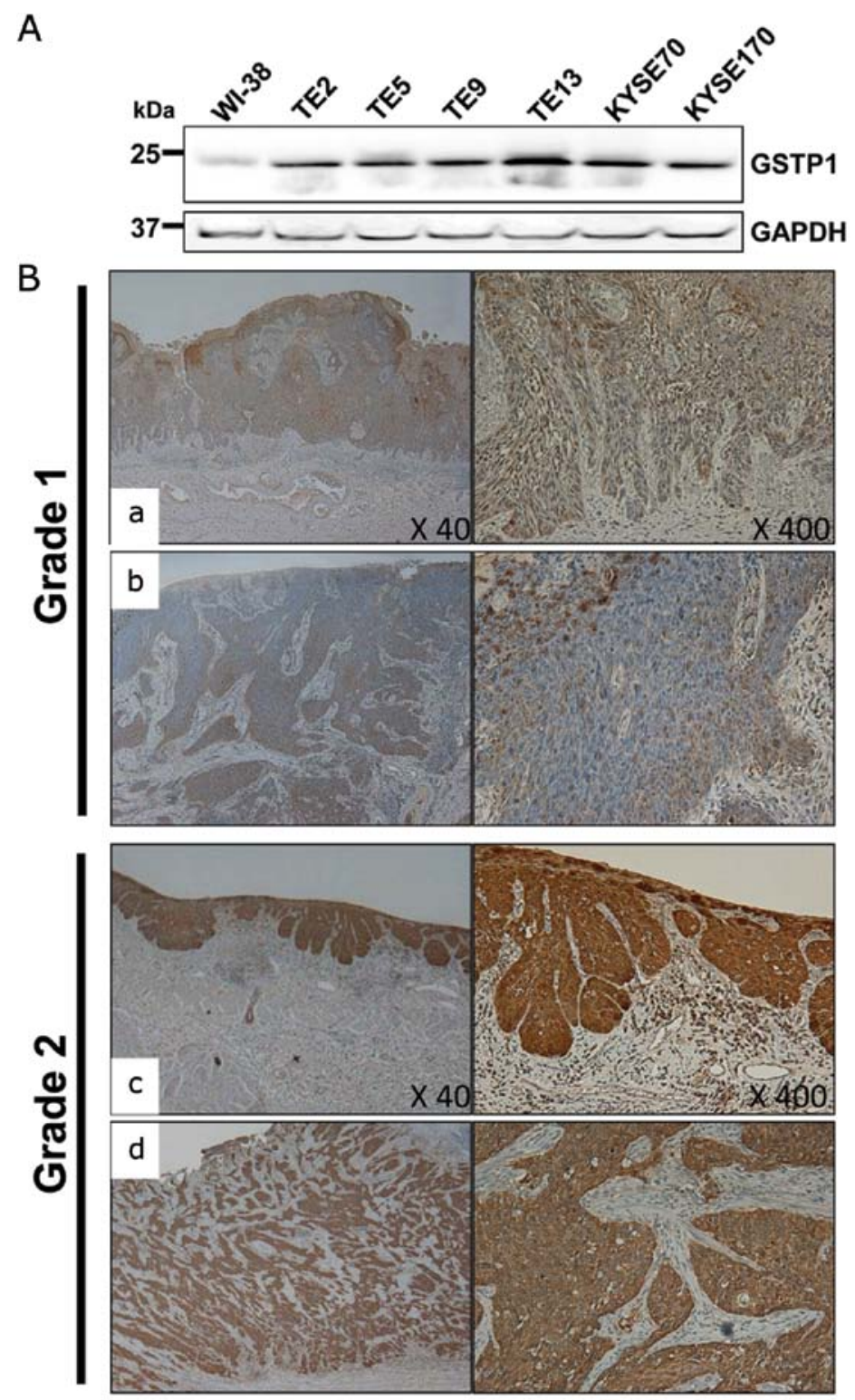

Figure 1. (A) Western blot analysis using an antibody against glutathione S-transferase P1 (GSTP1) in 6 esophageal squamous cell carcinoma (ESCC) cell lines (TE2, TE5, TE9, TE13, KYSE70 and KYSE170) and the normal fibroblast cell line WI-38. (B) Immunohistochemical images of GSTP1. (a and b) Low GSTP1 protein expression in grade 1 ESCC tissues; (c and d) high GSTP1 protein expression in grade 2 ESCC tissues (original magnification, $\mathrm{x} 40$; and a higher magnification view, $\mathrm{x} 400$ ).

Overall survival and clinicopathological features according to GSTP1 grade. Thirty-six patients had tumors that showed a low GSTP1 protein expression level defined as grade 1 (Fig. 1B-a and -b), whereas 39 had tumors that showed a high GSTP1 protein expression level defined as grade 2 (Fig. 1B-c and -d). The $\kappa$-value between the classifications of the two reviewers was 0.893 (almost perfect). The overall 5-year survival rate of all patients was $63.5 \%$ and Fig. 2 A showed the results of a survival analysis according to the GSTP1 grade. The 5 -year survival rate was $78.5 \%$ for grade 1 patients and $51.2 \%$ for grade 2 patients. There were significant differences in the survival rates between both groups $(\mathrm{p}=0.027)$.

Table I summarizes the results of the univariate and multivariate analyses of the prognostic factors associated with overall survival. Macroscopic type 3 or 4 disease $(p=0.001)$, lymph node metastasis $(\mathrm{p}=0.010)$ and grade 2 GSTP1 expres- sion $(\mathrm{p}=0.029)$ were independently associated with a poor prognosis.

The 10 clinicopathological factors related to the GSTP1 grade in tumor specimens were analyzed (Table II, the Chi-squared test and the logistic regression model). A tumor size $>40 \mathrm{~mm}(\mathrm{p}=0.007)$ and venous invasion $(\mathrm{p}=0.011)$ were identified as independent factors associated with grade 2 GSTP1 expression.

Relationship between the GSTP1 expression level and the efficacy of adjuvant chemotherapy. With regard to the subgroup analysis among the 44 patients who did not undergo adjuvant chemotherapy, there were no significant differences in survival between the grade 1 and grade 2 groups (5-year rate, 51.7 vs. $59.9 \%, \mathrm{p}=0.979$ ) (Fig. 2B). On the other hand, among the 31 patients undergoing adjuvant chemotherapy, the grade 1 
Table I. Results of the univariate and multivariate analyses of the prognostic factors associated with overall survival.

\begin{tabular}{|c|c|c|c|c|c|}
\hline & \multirow[b]{2}{*}{$\mathrm{n}$} & \multirow[b]{2}{*}{ 5-year OS (\%) } & \multirow{2}{*}{$\frac{\text { Univariate analysis }}{\text { p-value }}$} & \multicolumn{2}{|c|}{ Multivariate analysis } \\
\hline & & & & HR $(95 \% \mathrm{CI})$ & p-value \\
\hline Gender & & & 0.715 & & \\
\hline Male & 64 & 62.7 & & & \\
\hline Female & 11 & 68.6 & & & \\
\hline Age, years & & & 0.094 & & \\
\hline$<65$ & 50 & 56.8 & & & \\
\hline$\geq 65$ & 25 & 77.4 & & & \\
\hline Curability & & & 0.013 & & \\
\hline Curative resection & 54 & 70.0 & & & \\
\hline Non-curative resection & 21 & 45.4 & & & \\
\hline Main tumor location & & & 0.048 & & \\
\hline Lower thoracic esophagus & 26 & 48.9 & & & \\
\hline Middle or upper thoracic esophagus & 49 & 71.9 & & & \\
\hline Neoadjuvant chemotherapy & & & 0.241 & & \\
\hline Absent & 71 & 65.4 & & & \\
\hline Present & 4 & 40.0 & & & \\
\hline Macroscopic type & & & 0.001 & & 0.001 \\
\hline Type $0-2$ & 64 & 70.2 & & 1 & \\
\hline Type 3 and 4 & 11 & 27.3 & & $4.200(1.751-10.071)$ & \\
\hline Predominant differentiation & & & 0.358 & & \\
\hline Well or moderately differentiated & 52 & 69.3 & & & \\
\hline Poorly differentiated or others & 23 & 51.7 & & & \\
\hline Depth of tumor invasion (pT) & & & 0.094 & & \\
\hline $\mathrm{pT} 1$ or $\mathrm{pT} 2$ & 44 & 68.4 & & & \\
\hline pT3 or pT4 & 31 & 55.7 & & & \\
\hline Tumor size (mm) & & & 0.022 & & \\
\hline$<40$ & 39 & 74.5 & & & \\
\hline$\geq 40$ & 36 & 51.4 & & & \\
\hline Lymphatic invasion & & & 0.007 & & \\
\hline Absent & 34 & 77.9 & & & \\
\hline Present & 41 & 51.8 & & & \\
\hline Venous invasion & & & 0.019 & & \\
\hline Absent & 42 & 76.3 & & & \\
\hline Present & 33 & 47.5 & & & \\
\hline Infiltrative growth pattern & & & 0.181 & & \\
\hline Expansive pattern & 16 & 78.6 & & & \\
\hline Intermediate or infiltrative pattern & 58 & 59.2 & & & \\
\hline Intramural metastasis & & & 0.336 & & \\
\hline Absent & 71 & 64.2 & & & \\
\hline Present & 4 & 50.0 & & & \\
\hline Lymph node metastasis & & & 0.006 & & 0.010 \\
\hline Absent & 34 & 79.6 & & 1 & \\
\hline Present & 41 & 50.0 & & $3.396(1.335-8.637)$ & \\
\hline GSTP1 & & & 0.029 & & 0.029 \\
\hline Grade 1 & 36 & 78.5 & & 1 & \\
\hline Grade 2 & 39 & 51.2 & & $2.704(1.107-6.604)$ & \\
\hline
\end{tabular}

OS, overall survival; HR, hazard ratio; CI, confidence interval; GSTP1, glutathione S-transferase P1. 


\section{A}
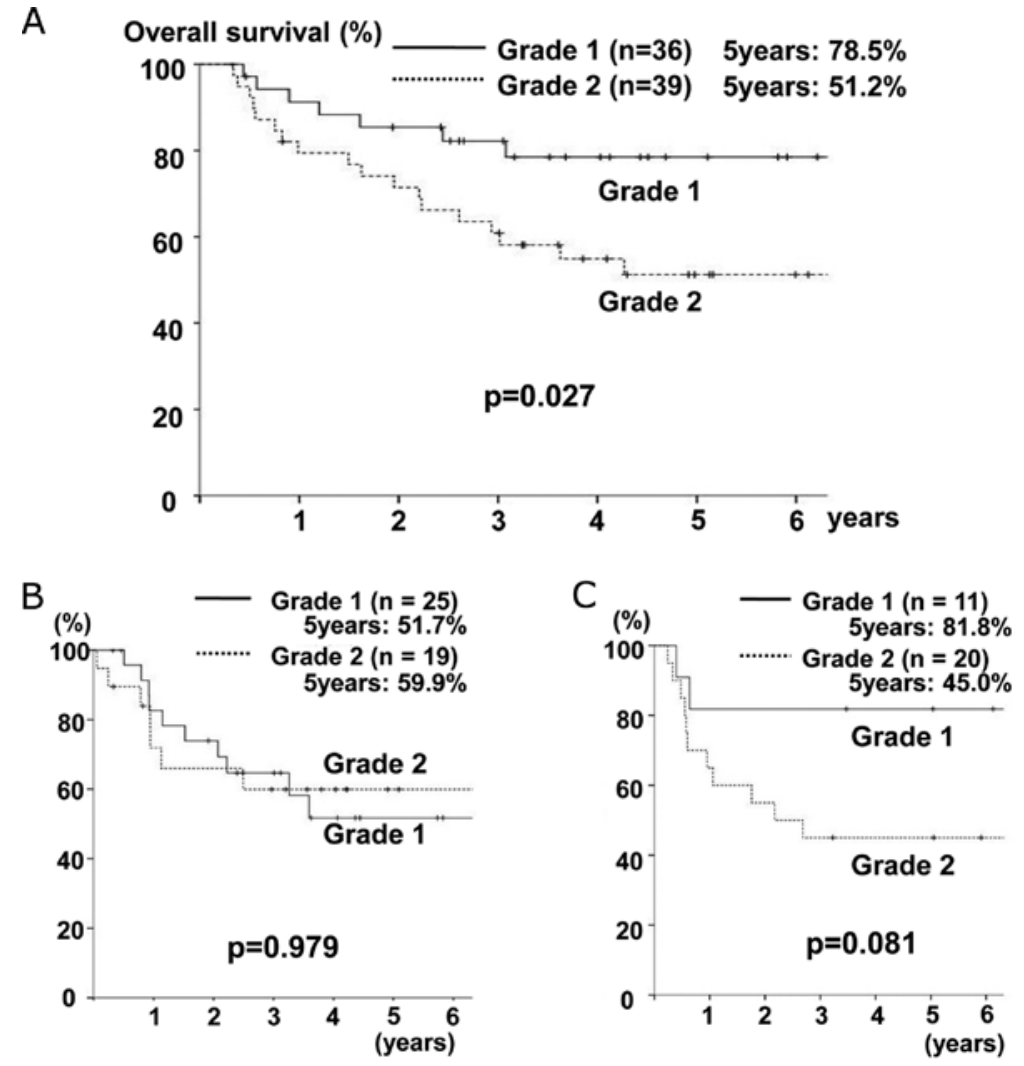

Figure 2. (A) Results of an analysis of the overall survival according to the grade of glutathione S-transferase P1 (GSTP1) staining in esophageal squamous cell carcinoma (ESCC) tissues. (B) Results of an analysis of the overall survival among 44 patients who did not undergo adjuvant chemotherapy. (C) Results of an analysis of the overall survival among 31 patients who underwent adjuvant chemotherapy.
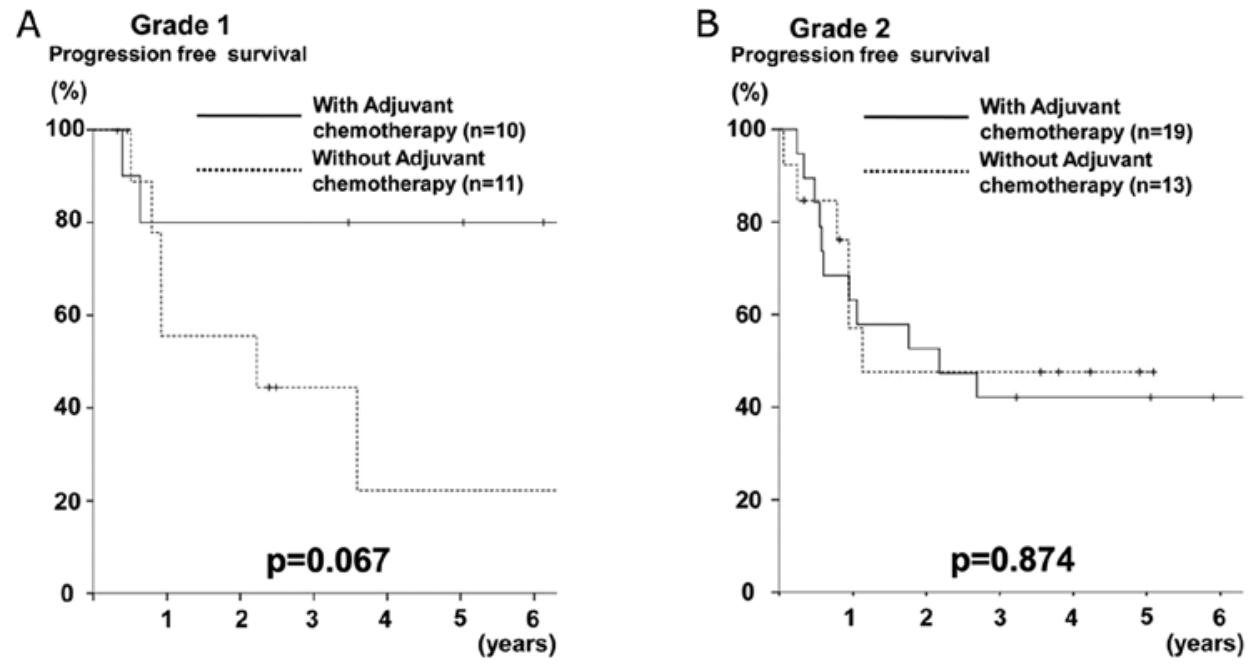

Figure 3. Subgroup analysis of progression-free survival among the pStage II, III, or IV patients in the (A) grade 1 group and (B) grade 2 group.

group had a better prognosis than the grade 2 group (5-year rate, 81.8 vs. $45.0 \%)$. There were, however, no significant differences between the groups ( $\mathrm{p}=0.081$ ) (Fig. 2C).

Furthermore, a subgroup analysis of progression-free survival among the pStage II, III, or IV patients according to the GSTP1 grade was performed. In the grade 1 group, the patients who underwent adjuvant chemotherapy were shown to have a better prognosis than those who did not undergo adjuvant chemotherapy $(\mathrm{p}=0.067)$ (Fig. 3A), whereas no difference was observed in the grade 2 group ( $p=0.874$ ) (Fig. 3B).

\section{Discussion}

GST expression has been widely detected in various organs and tumors, such as prostate cancer, colorectal cancer, breast cancer, gastric cancer and esophageal cancer $(21,22)$. GST enzymes catalyze the conjugation of toxic and carcinogenic electrophilic molecules to GSH and their activities constitute an important cellular protection mechanism for many types of damage, such as those that involve the activation of phase II detoxification enzymes $(11,23)$. In mammals, 7 classes of 
Table II. Results of the univariate and multivariate analyses of the 10 clinicopathological factors as related to the GSTP1 expression in the tumor specimens.

\begin{tabular}{|c|c|c|c|c|c|c|}
\hline & \multirow{2}{*}{$\mathrm{n}$} & \multirow{2}{*}{$\begin{array}{c}\text { Grade } 1 \\
(\mathrm{n}=36)\end{array}$} & \multirow{2}{*}{$\begin{array}{c}\text { Grade } 2 \\
(\mathrm{n}=39)\end{array}$} & \multirow{2}{*}{$\frac{\text { Univariate analysis }}{\text { p-value }}$} & \multicolumn{2}{|c|}{ Multivariate analysis } \\
\hline & & & & & $\mathrm{RR}(95 \% \mathrm{CI})$ & $\mathrm{p}$-value \\
\hline Gender & & & & 0.855 & & \\
\hline Male & 64 & 31 & 33 & & & \\
\hline Female & 11 & 5 & 6 & & & \\
\hline Age, years & & & & 0.327 & & \\
\hline$<65$ & 50 & 22 & 28 & & & \\
\hline$\geq 65$ & 25 & 14 & 11 & & & \\
\hline Main tumor location & & & & 0.091 & & \\
\hline Lower thoracic esophagus & 26 & 9 & 17 & & & \\
\hline Middle or upper thoracic esophagus & 49 & 27 & 22 & & & \\
\hline Macroscopic type & & & & 0.403 & & \\
\hline Type $0-2$ & 64 & 32 & 32 & & & \\
\hline Type 3 and 4 & 11 & 4 & 7 & & & \\
\hline Tumor size (mm) & & & & 0.015 & & 0.007 \\
\hline$<40$ & 39 & 24 & 15 & & 1 & \\
\hline$\geq 40$ & 36 & 12 & 24 & & $4.193(1.478-11.897)$ & \\
\hline Lymphatic invasion & & & & 0.030 & & \\
\hline Absent & 34 & 21 & 13 & & & \\
\hline Present & 41 & 15 & 26 & & & \\
\hline Venous invasion & & & & 0.024 & & 0.011 \\
\hline Absent & 42 & 25 & 17 & & 1 & \\
\hline Present & 33 & 11 & 22 & & $3.918(1.367-11.230)$ & \\
\hline Infiltrative growth pattern & & & & 0.211 & & \\
\hline Expansive pattern & 16 & 10 & 6 & & & \\
\hline Intermediate or infiltrative pattern & 58 & 26 & 32 & & & \\
\hline Intramural metastasis & & & & 0.344 & & \\
\hline Absent & 71 & 35 & 36 & & & \\
\hline Present & 4 & 1 & 3 & & & \\
\hline Lymph node metastasis & & & & 0.088 & & \\
\hline Absent & 34 & 20 & 14 & & & \\
\hline Present & 41 & 16 & 25 & & & \\
\hline
\end{tabular}

GSTP1, glutathione S-transferase P1; RR, relative risk; CI, confidence interval.

GSTs have been identified on the basis of amino acid sequence similarities, substrate specificity and immunological cross reactivity, such as GSTA, GSTM and GSTP (23). In the normal esophageal epithelium, several GST variants are expressed and GSTP1 is the main one (23).

For many types of cancers, including ESCC, the role of the GST protein has been discussed in the context of the variants of GST and the polymorphisms of each variant. In ESCC, many authors have reported several genotypes of GSTP1, such as lle $105 \mathrm{Val}$ and Ala 114 Val (13,22-24). However, these differences among the several variants or genotypes are conflicting between reports. In the present study, we simply assessed the relationship between GSTP1 protein expression and various clinicopathological parameters in ESCC (Fig. 1; Table II) and we found that high levels of GSTP1 expression, which were significantly associated with severe venous invasion and larger tumor size, led to poor prognosis (Fig. 2A; Table I). Moreover, the reproducibility of our classification of GSTP1 expression was found to be 'almost perfect' ( $\kappa$-value, 0.893 ) when all slides were assessed by another independent observer. These findings indicate that our classification of GSTP1 expression is a simple and reproducible predictor of the prognosis of ESCC.

There are two important reasons that we focused on GSTP1 expression in ESCC. The first is that GSTP1 has two tumor-protective roles involving the deactivation of anticancer reagents and the inhibition of signaling pathways that lead to apoptosis through the inhibition of the c-Jun N-terminal kinase (JNK). The deactivation of anticancer reagents by GST expression has been reported in many types of cancers, 
including ESCC, and it has been considered one of the main reasons for the acquisition of resistance to chemotherapeutic agents $(25,26)$. Furthermore, several GSTs have been shown to be associated with members of the mitogen-activated protein kinase (MAPK) pathway, such as JNK and p38, which is involved in cell survival and cell death signaling $(23,27,28)$. Based on these two major roles, we aimed to ascertain whether GSTP1 also affects cancer prognosis in ESCC.

The second reason is that GSTP1 expression is partially regulated by the Nrf2 gene, which is a transcriptional factor that is frequently upregulated in lung cancer, esophageal cancer and several other squamous cell carcinomas $(29,30)$. In ESCC cell lines and primary samples, mutations in Nrf2 are frequently reported (31). Therefore, we considered whether the high expression of GSTP1 may be partially affected by the activation of $\mathrm{Nrf} 2$.

In our study, the majority of patients treated by adjuvant chemotherapy with a low GSTP1 protein expression level showed better prognosis than the patients with a high GSTP1 expression level. This tendency was not shown in the patients with high GSTP1 protein expression level (Fig. 3). These results may indicate the role of GSTP1 for the detoxification of anticancer drugs in ESCC.

Since the publication of the results of the JCOG 9907 study, neoadjuvant chemotherapy followed by radical esophagectomy has been accepted as the standard therapeutic approach for resectable cStage II/III esophageal cancer in Japan (32). However, the clinical response rate of preoperative chemotherapy is only $38 \%$, which is not sufficient. Therefore, it seems to be quite important to develop predictive factors for the response to chemotherapy for patients who are unlikely to derive benefits from such therapy.

Retrospective analysis in a relatively small case series was a limitation of the present study, and a conflicting result regarding the utility of GSTP1 expression has also been reported (14). Therefore, our results need to be confirmed through additional studies of a large number of patients, and the clinical significance of GSTP1 in the prediction of the response to chemotherapy must be established in ESCC. If the relationship between the GSTP1 expression level and efficacy of chemotherapy is clinically confirmed, then the expression level may also have the potential to be used as a preoperative marker for the effect of neoadjuvant chemotherapy.

In conclusion, we showed that high GSTP1 protein expression in ESCC tissue is a sensitive marker of poor prognosis, and the resistance to adjuvant chemotherapy may be influenced by high GSTP1 expression. These findings indicate that classification of GSTP1 expression may be used as a simple, accurate, and reproducible predictor of prognosis and drug resistance for ESCC patients.

\section{References}

1. Kamangar F, Dores GM and Anderson WF: Patterns of cancer incidence, mortality, and prevalence across five continents: defining priorities to reduce cancer disparities in different geographic regions of the world. J Clin Oncol 24: 2137-2150, 2006.

2. De Vita F, Di Martino N, Orditura M, Cosenza A, Galizia G, Del Genio A and Catalano G: Preoperative chemoradiotherapy for squamous cell carcinoma and adenocarcinoma of the esophagus: a phase II study. Chest 122: 1302-1308, 2002.
3. Hofstetter W, Swisher SG, Correa AM, Hess K, Putnam JB Jr, Ajani JA, Dolormente M, Francisco R, Komaki RR, Lara A, Martin F, Rice DC, Sarabia AJ, Smythe WR, Vaporciyan AA, Walsh GL and Roth JA: Treatment outcomes of resected esophageal cancer. Ann Surg 236: 376-384, 2002.

4. Medical Research Council Oesophageal Cancer Working Group: Surgical resection with or without preoperative chemotherapy in oesophageal cancer: a randomised controlled trial. Lancet 359: 1727-1733, 2002.

5. Cooper JS, Guo MD, Herskovic A, Macdonald JS, Martenson JA Jr, Al-Sarraf M, Byhardt R, Russell AH, Beitler JJ, Spencer S, Asbell SO, Graham MV and Leichman LL: Chemoradiotherapy of locally advanced esophageal cancer: long-term follow-up of a prospective randomized trial (RTOG 85-01). Radiation Therapy Oncology Group. JAMA 281: 1623-1627, 1999.

6. McKinney A, Sharp L, Macfarlane GJ and Muir CS: Oesophageal and gastric cancer in Scotland 1960-90. Br J Cancer 71: 411-415, 1995.

7. Ando N, Ozawa S, Kitagawa Y, Shinozawa Y and Kitajima M: Improvement in the results of surgical treatment of advanced squamous esophageal carcinoma during 15 consecutive years. Ann Surg 232: 225-232, 2000.

8. Coles BF and Kadlubar FF: Detoxification of electrophilic compounds by glutathione S-transferase catalysis: determinants of individual response to chemical carcinogens and chemotherapeutic drugs? Biofactors 17: 115-130, 2003.

9. Matthias C, Jahnke V, Fryer AA and Strange RC: Influence of glutathione s-transferase and cytochrome $\mathrm{p} 450$ polymorphisms on prognosis of head and neck cancer. Laryngorhinootologie 81: 406-412, 2002 (In German).

10. Anderer G, Schrappe M, Brechlin AM, Lauten M, Muti P, Welte $\mathrm{K}$ and Stanulla M: Polymorphisms within glutathione S-transferase genes and initial response to glucocorticoids in childhood acute lymphoblastic leukaemia. Pharmacogenetics 10: 715-726, 2000.

11. Stoehlmacher J, Park DJ, Zhang W, Groshen S, Tsao-Wei DD, $\mathrm{Yu} \mathrm{MC}$ and Lenz HJ: Association between glutathione S-transferase P1, T1, and M1 genetic polymorphism and survival of patients with metastatic colorectal cancer. J Natl Cancer Inst 94: 936-942, 2002.

12. Sweeney C, Ambrosone CB, Joseph L, Stone A, Hutchins LF, Kadlubar FF and Coles BF: Association between a glutathione S-transferase A1 promoter polymorphism and survival after breast cancer treatment. Int J Cancer 103: 810-814, 2003.

13. Lee JM, Wu MT, Lee YC, Yang SY, Chen JS, Hsu HH, Huang PM, Kuo SW, Lee CJ and Chen CJ: Association of GSTP1 polymorphism and survival for esophageal cancer. Clin Cancer Res 11: 4749-4753, 2005.

14. Wang Z, He W, Yang G, Wang J, Wang Z, Nesland JM, Holm R and Suo Z: Decreased expression of GST pi is correlated with a poor prognosis in human esophageal squamous carcinoma. BMC Cancer 10: 352, 2010.

15. Ueda Y, Shiozaki A, Itoi H, Okamoto K, Fujiwara H, Ichikawa D, Kikuchi S, Fuji N, Itoh T, Ochiai T, Komatsu S and Yamagishi H: Intraoperative pathological investigation of recurrent nerve nodal metastasis can guide the decision whether to perform cervical lymph node dissection in thoracic esophageal cancer. Oncol Rep 16: 1061-1066, 2006

16. Shiozaki A, Yamagishi H, Itoi H, Fujiwara H, Kikuchi S, Okamoto K, Ichikawa D, Fuji N, Ochiai T, Sonoyama T and Ueda Y: Long-term administration of low-dose cisplatin plus 5-fluorouracil prolongs the postoperative survival of patients with esophageal cancer. Oncol Rep 13: 667-672, 2005.

17. Sobin LH, Gospodarowicz MK and Wittekind C (eds): International Union Against Cancer. TNM Classification of Malignant Tumours. 7th edition. Hoboken, NJ, Wiley-Blackwell, pp73-77, 2010.

18. Kato H, Miyazaki T, Nakajima M, Fukuchi M, Manda R and Kuwano H: Value of positron emission tomography in the diagnosis of recurrent oesophageal carcinoma. Br J Surg 91: 1004-1009, 2004.

19. Roedl JB, Harisinghani MG, Colen RR, Fischman AJ, Blake MA, Mathisen DJ and Mueller PR: Assessment of treatment response and recurrence in esophageal carcinoma based on tumor length and standardized uptake value on positron emission tomographycomputed tomography. Ann Thorac Surg 86: 1131-1138, 2008.

20. Fleiss JL: Measuring nominal scale agreement among many rates. Psychol Bull 76: 378-382, 1971. 
21. Nakajima T, Wang RS, Nimura Y, Pin YM, He M, Vainio $H$, Murayama N, Aoyama T and Iida F: Expression of cytochrome P450s and glutathione S-transferases in human esophagus with squamous-cell carcinomas. Carcinogenesis 17: 1477-1481, 1996.

22. Laborde E: Glutathione transferases as mediators of signaling pathways involved in cell proliferation and cell death. Cell Death Differ 17: 1373-1380, 2010.

23. Rossini A, Rapozo DC, Soares Lima SC, Guimarães DP, Ferreira MA, Teixeira R, Kruel CD, Barros SG, Andreollo NA, Acatauassú R, Matos HJ, Albano RM and Pinto LF: Polymorphisms of GSTP1 and GSTT1, but not of CYP2A6, CYP2E1 or GSTM1, modify the risk for esophageal cancer in a western population. Carcinogenesis 28: 2537-2542, 2007.

24. Li D, Dandara C and Parker MI: The $341 \mathrm{C} / \mathrm{T}$ polymorphism in the GSTP1 gene is associated with increased risk of oesophageal cancer. BMC Genet 11: 47, 2010.

25. Peklak-Scott C, Smitherman PK, Townsend AJ and Morrow CS Role of glutathione S-transferase P1-1 in the cellular detoxification of cisplatin. Mol Cancer Ther 7: 3247-3255, 2008.

26. Miyake T, Nakayama T, Naoi Y, Yamamoto N, Otani Y, Kim SJ, Shimazu K, Shimomura A, Maruyama N, Tamaki Y and Noguchi S: GSTP1 expression predicts poor pathological complete response to neoadjuvant chemotherapy in ER-negative breast cancer. Cancer Sci 103: 913-920, 2012

27. Adler V, Yin Z, Fuchs SY, Benezra M, Rosario L, Tew KD, Pincus MR, Sardana M, Henderson CJ, Wolf CR, Davis RJ and Ronai Z: Regulation of JNK signaling by GSTp. EMBO J 18 : $1321-1334,1999$.
28. Sau A, Filomeni G, Pezzola S, D'Aguanno S, Tregno FP, Urbani A, Serra M, Pasello M, Picci P, Federici G and Caccuri AM: Targeting GSTP1-1 induces JNK activation and leads to apoptosis in cisplatin-sensitive and -resistant human osteosarcoma cell lines. Mol Biosyst 8: 994-1006, 2012.

29. Hu Y, Ju Y, Lin D, Wang Z, Huang Y, Zhang S, Wu C and Jiao S: Mutation of the Nrf2 gene in non-small cell lung cancer. Mol Biol Rep 39: 4743-4747, 2012.

30. Kim YR, Oh JE, Kim MS, Kang MR, Park SW, Han JY, Eom HS, Yoo NJ and Lee SH: Oncogenic NRF2 mutations in squamous cell carcinomas of oesophagus and skin. J Pathol 220: 446-451, 2010.

31. Shibata T, Kokubu A, Saito S, Narisawa-Saito M, Sasaki H, Aoyagi K, Yoshimatsu Y, Tachimori Y, Kushima R, Kiyono T and Yamamoto M: NRF2 mutation confers malignant potential and resistance to chemoradiation therapy in advanced esophageal squamous cancer. Neoplasia 13: 864-873, 2011.

32. Ando N, Kato H, Igaki H, Shinoda M, Ozawa S, Shimizu H, Nakamura T, Yabusaki H, Aoyama N, Kurita A, Ikeda K, Kanda T, Tsujinaka T, Nakamura K and Fukuda H: A randomized trial comparing postoperative adjuvant chemotherapy with cisplatin and 5-fluorouracil versus preoperative chemotherapy for localized advanced squamous cell carcinoma of the thoracic esophagus (JCOG9907). Ann Surg Oncol 19: 68-74, 2012. 